\title{
Unusual Maculopapular Rash on the Scalp of a Patient with Mediterranean Spotted Fever
}

\author{
Ivan Baltadzhiev Nedialka Popivanova
}

Department of Infectious Diseases, Parasitology and Tropical Medicine, Faculty of Medicine, Medical University of Plovdiv, and Clinic of Infectious Diseases, St. George University Hospital, Plovdiv, Bulgaria

\section{Significance of the Study}

- Rashes on the hairy part of the head have not been previously reported in Mediterranean spotted fever (MSF). We report a case of MSF with maculopapular rash on the scalp. This finding enriches our understanding of the clinical features of MSF.

\section{Keywords}

Mediterranean spotted fever · Alopecia · Maculopapular rash. Scalp

\begin{abstract}
Objective: To report a rare case of maculopapular rash on the scalp in a patient with Mediterranean spotted fever (MSF). Clinical Presentation and Intervention: A 58-yearold woman with breast cancer and chemotherapy-induced alopecia contracted MSF. Her clinical features were typical, except for a maculopapular rash covering the scalp. The diagnosis of MSF was confirmed by immunofluorescent assay. The disease had a favorable course and the patient was discharged in good condition. Conclusion: The rash on the scalp described in this report enriches our knowledge on the clinical characteristics of MSF.

(c) 2018 The Author(s)

Published by S. Karger AG, Basel
\end{abstract}

\section{Introduction}

Mediterranean spotted fever (MSF) is caused by Rickettsia conorii. The pathogen is transmitted to humans by the brown dog tick Rhipicephalus sanguineus, assumed to be both the vector and reservoir of infection. Natural hosts of $R$. sanguineus are stray and pet dogs, which play a significant role in the epidemiological chain as intermediaries between ticks and humans. MSF has well-defined characteristics: eschar on the site of the tick bite, or tache noire; usually abrupt onset with fever and flu-like symptoms; and maculopapular rash diffusely spread on the body and extremities, involving the palms and feet. The rash often spares the face and does not spread to the hairy part of the head. The purpose of this report is to present an unusual localization of rash on the scalp in a patient with MSF. The latter has not been seen in our practice so far and has not been reported in the available literature.

\begin{tabular}{ll}
\hline KARGER & $\begin{array}{l}\text { () 2018 The Author(s) } \\
\text { Published by S. Karger AG, Basel Oparger }\end{array}$ \\
$\begin{array}{l}\text { E-Mail karger@karger.com } \\
\text { www.karger.com/mpp }\end{array}$ & $\begin{array}{l}\text { This is an Open Access article licensed under the Creative Commons } \\
\text { Attribution-NonCommercial-4.0 International License (CC BY-NC) } \\
\text { (http://www.karger.com/Services/OpenAccessLicense), applicable to } \\
\text { the online version of the article only. Usage and distribution for } \\
\text { commercial purposes requires written permission. }\end{array}$
\end{tabular}

Ivan Baltadzhiev

Department of Infectious Diseases, Parasitology and Tropical Medicine Faculty of Medicine, Medical University of Plovdiv

15A Vassil Aprilov Blvd., BG-4002 Plovdiv (Bulgaria)

E-Mail ivan_balt@yahoo.com 


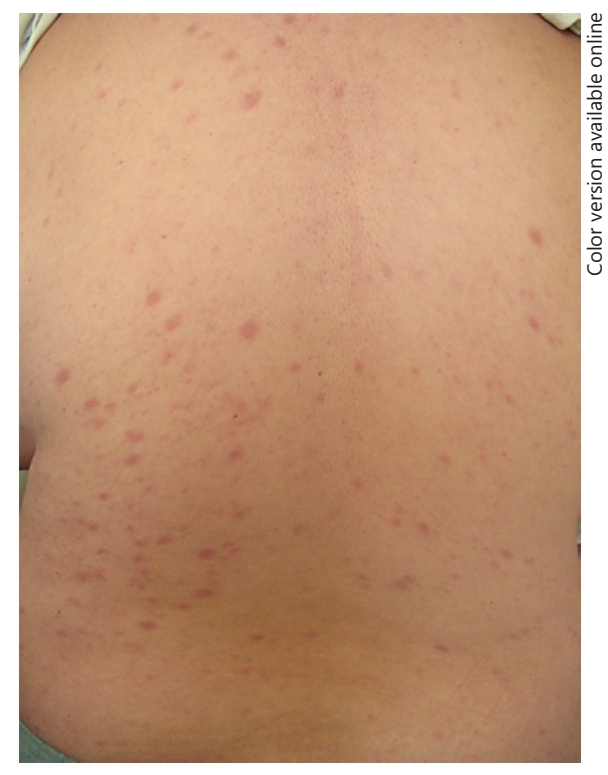

Fig. 1. Typical maculopapular rash on the body of the patient with Mediterranean spotted fever.

\section{Case Report}

A 58-year-old woman, who had often removed ticks from her pet dog, was admitted to our unit with a 4-day history of highgrade fever, chills, and myalgia, followed by a skin eruption. Her medical history included left mastectomy for breast cancer followed by chemotherapy and hair loss 1 month before. She was admitted to hospital 5 days after onset in a moderately impaired state. On examination, the patient showed a non-itching maculopapular rash, most notable on the trunk, involving the legs and arms, including the palms and feet (Fig. 1). The scarf from her head was removed and a maculopapular rash, typical for MSF, was observed on her scalp (Fig. 2). Tache noire was localized on the abdomen. Medical examination revealed a moderately enlarged liver, blood pressure of 113/70 $\mathrm{mm} \mathrm{Hg}$, and a heart rate of $90 \mathrm{bpm}$. Laboratory blood tests showed decreased hemoglobin level, moderate leukocytosis, hypoalbuminemia, moderately elevated aminotransferase activity, and mildly elevated levels of urea and creatinine.

The disease was diagnosed based on epidemiological and clinical criteria and confirmed by a fourfold increase in the antibody titer to the specific $R$. conorii antigen by indirect immunofluorescent assay, performed at the Reference Rickettsioses Laboratory, Military Medical Academy, Sofia (Rickettsia conorii-Spot IF, bioMérieux, Marcy-l'Étoile, France). IgM titers $>64$ and IgG titers $\geq 128$ were considered indicative of acute infection. The patient was given oral doxycycline $100 \mathrm{mg}$ twice a day for 10 days. She showed clinical improvement within 1 week of initiating treatment and was discharged from the hospital in a generally good condition.

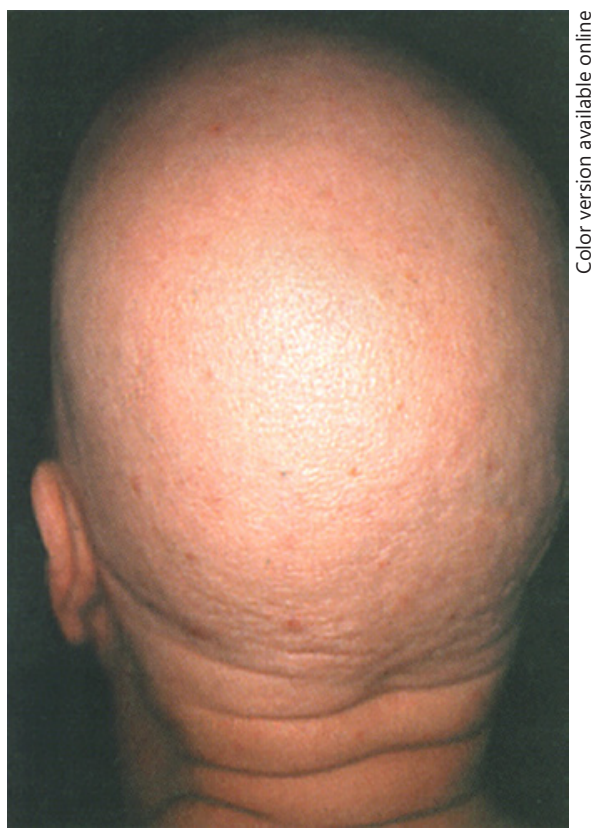

Fig. 2. Maculopapular rash on the scalp skin of the patient with Mediterranean spotted fever.

\section{Discussion}

MSF has typical clinical features, including the classic triad: a pathognomonic eschar (tache noire), fever, and maculopapular rash. The symptoms and signs as well as the epidemiological data (resident in an endemic region during the transmission season, living conditions and lifestyle, encountering ticks and tick bites) made the diagnosis very likely. However, several atypical cases of infectious diseases transmitted by zoonotic agents have been described in the literature [1-3]. For example, a case of tache noire in a patient with $\mathrm{Q}$ fever was reported recently [4].

Similarly, this case is unique. In a previous study, we observed a cohort of 549 hospitalized patients with MSF. Of them, 77\% had tache noire de Pieri [5]. The skin rash occurred most often 3-4 days after the initial fever. It was maculopapular or papular in nature according to the predominant type of the rash units. Overall, we found a skin rash in $99 \%$ of patients. The eruption was located on the limbs and trunk, involving the wrists and ankles, often sparing the face, and almost always present on the palms and soles. The rash involved the palms and soles in 425 (78\%) of our patients. Facial rash $(191,35 \%)$ was not frequent. A special feature of skin eruption in MSF is the fact that the rash units are not uniform in size and convexity; 
some are more prominent and pink-red in color, others are flatter and brownish. In our experience we have not seen an MSF rash on the hairy scalp, although tache noire in similar locations was noted often, especially in children [5]. Moreover, scalp efflorescences have not been observed by other MSF researchers in Bulgaria, and no similar descriptions in the available literature were found [6, 7]. As is well known, many diseases show a rash on the scalp, but MSF is not listed among them [8-10].

Why was it difficult to detect a rash on the scalp of a patient with MSF? Firstly, noticing a rash on the scalp is problematic due to the hair follicles. In our case, the alopecia probably made it possible to be observed. Secondly, it is possible that the malignancy and subsequent chemotherapy influenced the expression of the condition. An analogous case has not been described in the course of our more than two decades long investigations of MSF in Bulgaria [5].

\section{References}

1 Li JJ, Sheng ZK, Tu S, Bi S, Shen XM, Sheng JF. Acute brucellosis with myelodysplastic syndrome presenting as pancytopenia and Fever of unknown origin. Med Princ Pract. 2012;21(2):183-5.

2 Siddiqui N, St Peter DM, Marur S. Ticks and salt: an atypical case of neuroborreliosis. J Community Hosp Intern Med Perspect. 2017 Dec;7(6):358-62.

3 Enger A, Strand ØA, Ranheim T, Hellum KB. Exflagellation of microgametocytes in Plasmodium vivax malaria: a diagnostic conundrum. Med Princ Pract. 2004 Sep-Oct;13(5): 298-300.

\section{Conclusion}

The rash on the scalp described in this paper contributes to our knowledge on the clinical characteristics of MSF. It proves that MSF can affect any part of the human body.

\section{Statement of Ethics}

The study was approved by the Ethics Committee of Medical University of Plovdiv.

\section{Disclosure Statement}

The authors report no conflicts of interest.
4 Fiore V, Mancini F, Ciervo A, Bagella P, Peruzzu F, Nunnari G, et al. Tache Noire in a Patient with Acute Q Fever. Med Princ Pract. 2018;27(1):92-4.

5 Baltadzhiev I, Popivanova N. Symptoms and syndromes in patients with Mediterranean spotted fever. In: Baltadzhiev I, editor. Twenty years MSF in the Plovdiv-endemic region of Bulgaria, ed 1. Plovdiv: Lax Book Publishers; 2015. p. 51-76.

6 Raoult D, Edouard S. Rickettsia: spotted fever group - RMSF, R. conori, R. africae, R. akari. Decision Support in Medicine. PLoS Negl Trop Dis. 2014;8:e3179.
7 Parola P, Paddock CD, Socolovschi C, Labruna MB, Mediannikov O, Kernif T, et al. Update on tick-borne rickettsioses around the world: a geographic approach. Clin Microbiol Rev. 2013 Oct;26(4):657-702.

8 Kang JH. Febrile Illness with Skin Rashes. Infect Chemother. 2015 Sep;47(3):155-66.

9 White S. Causes of a rash on the scalp skin. https://www.livestrong.com/article/224957causes-of-a-rash-on-the-scalp-skin (last updated August 14, 2017).

10 Oakley A. Diagnosis of scalp rashes https:// www.dermnetnz.org/topics/diagnosis-ofscalp-rashes. Hamilton, New Zealand, February 2016. 